$10-9-2017$

\title{
What do supervision officers do? Adult probation/parole officer workloads in a rural Western state
}

Adam K. Matz

University of North Dakota, adam.matz@und.edu

How does access to this work benefit you? Let us know!

Follow this and additional works at: https://commons.und.edu/cj-fac

Part of the Criminology and Criminal Justice Commons

\section{Recommended Citation}

Adam K. Matz. "What do supervision officers do? Adult probation/parole officer workloads in a rural Western state" (2017). Criminal Justice Faculty Publications. 1.

https://commons.und.edu/cj-fac/1

This Article is brought to you for free and open access by the Department of Criminal Justice at UND Scholarly Commons. It has been accepted for inclusion in Criminal Justice Faculty Publications by an authorized administrator of UND Scholarly Commons. For more information, please contact und.commons@library.und.edu. 


\title{
What do Supervision Officers do?
}

\section{Adult Probation/Parole Officer Workloads in a Rural Western State}

\begin{abstract}
For several decades time studies have been used as a decision making tool in criminal justice settings to assist in staffing allocation decisions. Despite their prevalence, these studies have rarely been documented in empirical journals or subjected to peer-review. Publication bias is a likely issue, with only those providing favorable results reaching a public audience. This study reviews the literature and documents a time study of probation and parole officer workloads conducted in a rural Western state. Results reveal probation and parole relies heavily on office-based interactions with probationers and parolees. An over-reliance on compliance enforcement, substantiated by other research in the state, suggests the transition to evidencebased practices and programs remains an ongoing and challenging process as officers continue to cope with caseloads that exceed national recommendations.
\end{abstract}

Keywords: probation, parole, caseload 


\section{What do Supervision Officers do?}

\section{Adult Probation/Parole Officer Workloads in a Rural Western State}

\section{Introduction}

The workload of probation and parole officers is often discussed in terms of caseload size. The American Probation and Parole Association (APPA) has received numerous requests from agencies interested in comparing their caseloads to other states. Aside from a single limited study (Bonczar, 2008), no state-by-state comparison has been compiled and made readily available, thoughAPPA has provided limited guidance (Burrell, 2006; Hanser, 2014). The degree to which excessive caseloads have a dampening effect on supervision quality and offender outcomes has remained a point of contention between practitioners, administrators, and researchers (Jalbert \& Rhodes, 2012; Jalbert, Rhodes, Flygare, \& Kane, 2010). That said, the work of probation/parole officers encompasses more than supervision of the offenders on their caseloads and focusing solely on this singular metric provides a limited perspective of the occupation. Fortunately, more nuanced examinations of officer workloads have been conducted over the past three decades (DeMichele, Payne, \& Matz, 2011), though they have rarely made their way into the empirical literature.

This study includes a review of probation/parole workload studies and documents the results of a recent project conducted for the rural Western state of Montana. The Montana Probation and Parole Division (MPPD), a subunit of the Montana Department of Corrections (MDOC), sought a workload study to supplement previous analyses conducted by the National Institute of Corrections (NIC) (Hardyman, 1999, 2001). This article provides a descriptive summary of MPPD’s time study, offering a profile of the work conducted by a statewide probation/parole agency, as well as delineating areas in which its officers perceived there were 
notable time constraints. Several exploratory analyses are presented which examine potential disparities in time associated with specific offender populations in terms of their geographic location, race, sex, and age.

\section{Literature review}

\section{Caseload Recommendations}

Caseload ratios persist as the administrative go-to method for calculating appropriate staffing allocations for safe offender management. In an issue paper for APPA, Burrell (2006) notes the difficulty of determining appropriate caseload sizes for probation/parole officers. The complexity (e.g., statewide, county, or municipal jurisdiction; adult or juvenile) of the community corrections field necessitates that each individual probation and/or parole agency allocate workload based on the unique needs of their jurisdiction. However, many jurisdictions lack the resources necessary to undertake such research. In response to this difficulty, Burrell reluctantly advocates for caseload standards to be staggered based on risk classification. Specifically, intensive supervision caseloads should exist at an officer-to-offender ratio of 1:20, moderate-to-high risk caseloads of 1:50, and low risk caseloads of 1:200. He further differentiated adult versus juvenile caseloads, with juvenile caseloads being slightly more restrictive. These caseload standards are conservative and may be unrealistic for some jurisdictions but the emphasis on allocation of staff to prioritize supervision of high risk offenders and minimize resources allocated to low risk offenders is universally applicable and in alignment with the tenets of evidence-based practices (EBP) (Jalbert \& Rhodes, 2012; Taxman \& Belenko, 2012), even if the exact ideal ratio remains uncertain.

To facilitate such an allocation Burrell (2006) advocated for the use of validated criminogenic risk/needs assessment instruments at regular intervals during supervision. Research 
has established that intervention intensity should be based on the individual's criminal propensity (Andrews, Bonta, \& Hoge, 1990; Latessa, 2004). Specifically, intensive programming should be reserved for those at greatest risk for reoffending, as mismatched over-programming, or mixing participants with different risk levels, can negatively impact low risk populations (Looman, Dickie,, \& Abracen, 2005).

Jalbert and colleagues (2010) note the reduction of caseloads for high-risk individuals, such as those placed on intensive supervision probation (ISP), has not always lead to the desired improvement in outcomes. The authors attribute such failures to two key issues; 1) reduced caseloads were not associated with the expected increase in treatment interactions, and 2) increased supervision intensity was focused too heavily on identifying and issuing technical (i.e., non-criminal) violations. That said, probation programs effectively integrating a rehabilitative model were found to have more success, achieving up to a 30\% reduction in recidivism (Jalbert \& Rhodes, 2012; Paparozzi \& Gendreau, 2005). In essence, reduced caseloads have been demonstrated to improve outcomes for medium-to-high risk probationers/parolees, but only if the increased supervision includes an appropriate level of relevant increased treatment and social work interactions, or an evidence-based hybrid model of supervision (Skeem \& Manchak, 2008; Taxman \& Belenko, 2012). It should be noted, however, that more research is needed to substantiate these results and that the optimum ratio of officers-to-offenders remains elusive. This is especially pertinent for medium and high risk populations. For low risk populations minimal interventions are necessary allowing for supervision officers to manage larger caseloads without sacrificing outcomes (Lowenkamp \& Latessa, 2005). 
Time Studies: History and Methods

Time studies utilize the development of detailed lists of operations to track tasks over a set period of time. The resulting data are used to make determinations about changes in business practices that will improve efficiency. The advent of the "time study" can be traced back to the 1880s industrial time and motion studies pioneered by Frederick W. Taylor (Miles, 1969). The 1881 Midvale Steel Company of Philadelphia time study was considered the first of its kind and laid the groundwork for time studies conducted in other fields including nursing (see Alghamdi, 2016) and criminal justice (American Prosecutors Research Institute [APRI] \& Bureau of Justice Assistance [BJA], 2002; DeMichele et al., 2011; Douglas, Tallarico, Freiss, \& wills, 2004; Flango \& Ostrom, 1996; Hurst, 1999; Kleiman, Lee, \& Ostrom, 2013; Lee, Kleiman, \& Ostrom, 2014; Nugent \& Miller, 2002; Ostrom, Kleiman, Lee, \& Roth, 2014). Though initially unpopular due to their association with piece-rate wage systems, they have steadily gained a reputation as a tool for improving various business operations. For social organizations, such as probation and parole, time studies are used primarily to understand the amount of time officers spend in contact with their offenders versus how much time is associated with other work activities (DeMichele et al., 2011). These studies have historically been driven by budgetary needs, not empiricism. Directors and administrators have relied on time studies to determine what tasks can be eliminated and to provide a more definitive justification for additional staff to the state legislature.

The workload assessment process is “....an iterative, participatory process...” whereby practitioners are actively engaged and involved throughout each stage of the research (Kleiman et al., 2013, p. 244). NCSC, when conducting workload assessments, utilizes a pseudo-Delphi process which relies on the input, feedback, and opinions of practitioners to support workload 
decisions (Helmer-Hirschberg, 1967). The Delphi process has been used in a variety of settings including social work, health, and education to assist in applied research problems (Anderst, Teran, Dowd, Simon, \& Schnitzer, 2015; Edwards, Hughes, \& Lord, 2013; Fletcher \& Marchildon, 2014; Gavrielides, 2008; Green, 2014). Practitioner feedback, in addition to the data obtained from time studies and supplemental staff surveys, may be used to inform a system of weighting which dictates which areas of community corrections work warrant the greatest attention (Chapman, 1972; Kleiman et al., 2013; Orme, 1988). The resulting weighted estimates provide a basis for a discussion by agency leaders on what activities should and should not be required of probation/parole officers, and incidentally where those activities should go (e.g., can extraneous paperwork be completed by an assistant instead of the officer?) (Kleiman et al., 2013). Estimates also prove informative to agency leaders in terms of prioritization; which activities should their officers prioritize and which should be minimized as non-essential.

The advancement of internet technology in the past decade has made sampling and data collection processes for time studies considerably quicker and less expensive. Online applications for officers to enter time use data associated with work activities are more efficient than previous paper-based processes. Early research estimated that time studies required an average of 20 minutes per day per officer, or roughly one work-day (about 7 hours), over a onemonth period (Bemus, Arling, \& Quigley, 1983). Sampling strategies have varied with some including all offices and officers (Tallarico, Douglas, \& Fogg, 2010; Tallarico, Douglas, Friess, \& Hall, 2009; Tallarico, Douglas, Kinney, \& Murphy, 2007; Tallarico, Douglas, Tomlinson, \& Hall, 2010), and others selecting a sub-sample. Larger agencies, such as statewide or urban departments, have tended to use a stratified sample of offices (Bercovitz, Bemus, \& Hendricks, 1993; Bemus, 1990; Sterling Associates, 2002; Washington Department of Corrections 
[WADOC], 2005) or officers (Griesse, 2008) while smaller agencies usually include all officers in their study (Bemus et al., 1983). Methodologically, some time studies have relied on random observations (in which officers are paged at specific time intervals to report the work being conducted at that time) in lieu of having officers self-report their activity information independently (Sterling Associates, 2002; WADOC, 2005). In terms of self-reporting activity information, some studies require documentation pertaining to a random sample of a given officer's caseload (Bercovitz et al., 1993; Bemus et al., 1983; Hardyman, 2001), while others have required documentation of all cases (Tallarico et al., 2007, 2009; Tallarico, Douglas, \& Fogg, 2010; Tallarico, Douglas, Tomlinson, \& Hall, 2010). The total length of time tracking activity information has ranged between four and eight weeks, with a recognition that four weeks yields similar results to longer data collection periods (Hardyman, 1999; 2001).

Time study outcomes vary. Published time studies tend to advocate the need for additional staff and improved resource allocation, though publication bias is a concern (Cooper, 2010). In Alabama NCSC recommended, with added input from an advisory committee, an additional 29 juvenile probation officers (Tallarico, Douglas, Tomlinson, \& Hall, 2010). The same organization recommended seven additional juvenile court officers and three secretaries in North Dakota (Tallarico, Douglas, \& Fogg, 2010), and 40 additional court services officers for the state of South Dakota (Tallarico et al., 2007). A 1990 Colorado study found a need for 32 probation officers (Bemus, 1990). An earlier study conducted by the National Council on Crime and Delinquency (NCCD) found a need for four additional adult probation and parole officers in North Dakota (Wagner \& Connell, 2004). Some time study researchers choose to provide the results with instructions for allocation computations without providing an explicit recommendation for increased staffing levels (Griesse, 2008; Hardyman, 1999, 2001; Sterling 
Associates, 2002; Tallarico et al., 2009; WADOC, 2005). Instead, these authors request that agency executives convene a working group that integrates the study results with agency standards and goals to garner a consensus-driven decision (Bemus, 1990). It is unclear to what extent these staffing recommendations have influenced legislative decisions.

Aside from staff allocation, time studies have also been used to prompt changes in agency practices. In a North Carolina study the need for risk re-classification became apparent as offenders were identified initially at a higher risk level than was warranted, unnecessarily draining valuable staff time (Cuddeback, Gayman, \& Bradley-Engen, 2011). In many reports time studies are used to determine the time parameters associated with cases at a specified supervision level, which is used to revise an officer's caseload limits and make recommendations for redistribution (Griesse, 2008). Results have also been supplemented with departmental audits and shortfalls in supervision contacts identified, areas in which agencies would subsequently work towards rectifying (Bemus, 1990). Finally, time studies have also been used to inform, or integrated with, the development of electronic case management systems (Bercovitz et al., 1993).

\section{Methods}

Consistent with the Delphi process adopted by NCSC (Kleiman et al., 2013), a workload advisory committee was established with MPPD that included representation from each region of the state consisting of administrators, supervisors, and probation/parole officers. A total of 17 individuals were formally associated with the committee; including representation from Council of State Governments Justice Center (CSGJC) and APPA. An initial onsite meeting was convened with the workgroup which included an overview of the relevant literature, the anticipated goals and process, as well as anticipated time to address other project needs of the division. Monthly conference calls and online meetings using software such as GoToMeeting 
were conducted throughout the subsequent year to develop and refine the time study methods and associated research instruments. Engaged in a task analysis, the committee was continually provided draft time study forms, most notably updated task lists, and then asked to review and discuss the areas that were less relevant to the job in Montana or notable areas pertinent to the job that were missing. The initial task list was compiled from prior probation/parole workload studies (Bemus, 1990; Bemus et al., 1983; Bercovitz et al., 1993; Cuddeback et al., 2011; Tallarico et al., 2007, 2009; Tallarico, Douglas, \& Fogg, 2010; Tallarico, Douglas, Tomlinson, \& Hall, 2010), including those conducted in Montana (Hardyman, 1999, 2001) and other related reports on probation and parole workloads (DeMichele, 2008; DeMichele \& Payne, 2007; DeMichele \& Payne, 2012; DeMichele et al., 2011; Payne \& DeMichele, 2011). The full task list exceeded 150 entries, well beyond what would be reasonable for officers to track and document. After nearly nine months of deliberation and refinement, the committee came to a final consensus, approving the inclusion of 35 case-specific tasks (see Table 2). An additional ten noncase-related activity codes were included in the study as well concerning documentation associated with the study itself, officer training, staff meetings, coworker support, administrative duties, miscellaneous mail/email/voicemails, staff leave, and public correspondence needs.

Once finalized, the time study instruments, along with the associated task lists, were transferred from paper form to a web-based application. To familiarize officers with the workload assessment process and encourage participation, two training webinars were conducted. The first webinar was open to all staff and provided a general overview of the workload assessment process, while the second webinar was limited to time study participants, based on a stratified random sample by region and specialization (Babbie, 2007), and involved a live demonstration of the web-based workload data collection instrument. Officers were 
encouraged to enter information on their activities daily. A training manual was also provided to staff as a supplemental resource, in addition to hyperlinks to recordings of the webinars.

The data collection took place over a four-week period from February 2-27, 2015. A preliminary check of the data after one week was conducted to ensure participants were utilizing the web-based application correctly and that data could be compiled and transferred accordingly. In addition to the information related to activities supplied by the study participants, MPPD also provided supplemental agency data pertaining to the probationers and parolees including demographical information, risk assessment scores, and classification levels.

\section{Sample}

MPPD is a statewide agency that administers adult probation and parole services for the state of Montana. The division includes 23 field offices and supervises more than 9,000 adult probationers and parolees. Headquartered in the state capital, MPPD also provides oversight for community-based programs including prerelease centers and treatment facilities. At the time of the study the division employed 158 probation/parole officers. Sixteen were classified as institutional probation and parole officers (or IPPOs), working within the institutions providing reentry planning to incarcerated individuals soon-to-be released to community supervision. Another eight were specifically designated as presentence investigation (PSI) writers. PSI writers do not carry a caseload. Fifteen officers worked intensive supervision probation, two were directly associated with the Smart program and possessed reduced caseloads, ten worked with sex offenders, six were assigned to work with treatment court participants, and another 14 possessed specialized caseloads concerning mental health, Native American, and reentry needs.

To reduce the burden on MPPD while still ensuring representation from each region of the state, a stratified random sample was utilized. Probation/parole officers were randomly 
selected by region and officer specialization in proportion to the number of officers deployed across each group throughout the state (Babbie, 2007). The division asked that all 16 IPPOs be included due to the uniqueness of their occupation. As a result, 107 out of 158 officers employed at the time of the study were selected for inclusion. Ensuring at least one officer of each specialization across all applicable regions was included, this resulted in 51 (of 88) general supervision officers, nine (of 15) intensive supervision officers, five (of six) mental health supervision officers, one (of one) Native American supervision specialists, seven (of eight) PSI writers, six (of seven) reentry specialists, two (of two) Smart Supervision Program Grant officers, one (of one) Treatment Accountability Program (TAP) officers, and five (of six) treatment court supervision officers. Three officers did not participate in the study due to transfers and other personnel moves. However, the other 104 officers did participate, netting a $97 \%$ response rate. Overall, this participation level represented $66 \%$ of the entire state workforce of MPPD adult probation/parole officers. For comparison, prior workload studies have been conducted with as few as 56 (Tallarico, Douglas, \& Fogg, 2010), to as many as 711 (Tallarico et al., 2009), participants depending on the size of the agency. Similar to prior research conducted in Montana (Hardyman, 1999, 2001), this study also included a random sample of cases from participating officers. Specifically, 50\% of a given officer's assigned caseload and all new cases or incidental contacts that occurred during the data collection period.

Table 1 displays demographic information on the 104 adult probation/parole officers that participated in the time study. Specializations are designated based on the primary function of each respective officer as defined by MPPD, not their position title. In some cases, officers may do work outside of this designated function. The majority of officers fall under general caseload supervision, classified as non-specialized (44.2\%). Specializations included IPPOs (15.4\%), ISP 
(5.8\%), mental health (4.8\%), Native American (1\%), PSI writers (6.7\%), reentry (3.8\%), sex offender (7.7\%), Smart probation (1.9\%), treatment accountability program (TAP) (1.9\%), and treatment court officers (6.7\%). MPPD is divided into six regions across the state, with one or more offices located in each jurisdiction.

Regional and demographic representation reflected in the study is approximate with their representation in the state with 21 officers in region I (20.2\%), 23 in region II (22.1\%), 20 in region III (19.2\%), 19 in region IV (18.3\%), 14 in region V (13.5\%), and seven in region VI (6.7\%). In terms of gender, $51 \%$ of officers were male and $49 \%$ female. The average age was 43 years and officers averaged six years in their current position. Due to confidentiality concerns demographic information pertaining to officer race was not provided but a closely-related survey conducted shortly after the time study found 90\% of a sample of 114 MPPD officers selfidentified as white, 3\% as Hispanic/Latino, 2\% Native American or American Indian, 2\% Asian, 1\% African American, and the remaining 3\% as other [Citation Omitted for Peer Review].

Table 1 presents demographic data pertaining to the 4,140 probationers and parolees officers had contact with during the study. BJS reported a total probation/parole population of 9,700 for the state at the end of 2014 (Kaeble, Bonczar, \& Maruschak, 2015), indicating that this study captured work associated with about $42 \%$ of that population. About half of these individuals (49.4\%) were associated with non-specialized caseloads, a quarter with IPPOs (25.0\%), and the remaining quarter split across specialized programs and caseloads. The proportion of probationers/parolees under supervision by geographic region was similar to that of the officers. Just under a quarter (23.1\%) of probationers/parolees were located in region I, with one-fifth located in region II and region IV. About 17\% were located in region III, 12\% in region $\mathrm{V}$, and $7 \%$ in region VI. The proportion of sampled officers by region was within $2-3 \%$ of the 
proportion of sampled probationers/parolees by region. Probationers and parolees in Montana were mostly male (77.3\%) and white (78.7\%). However, the Native American or American Indian representation at $18.1 \%$ is more than double their representation in the general population (see also Cobb \& Mullins, 2009). The average age of the probationers and parolees was 38.

\section{Insert Table 1}

\section{Findings}

Table 2 provides descriptive data concerning 19,094 case and non-case related activities recorded by the time study participants. All figures include travel and wait time in addition to the raw time associated with a given activity. These data provide answers to three research questions; 1) what are the most common tasks associated with supervising probationers/parolees, as well as non-case-related activities, 2) how much time is associated with these tasks, and 3) is quality being sacrificed for timeliness?

The standard case contact and interview with probationers and parolees was the most frequent activity documented, comprising $18.1 \%$ of all officer activity. With the exception of administrative caseloads and those on unsupervised release, probationers and parolees are required to meet regularly with their supervising officer as a condition of their supervision (Hanser, 2014; Stohr \& Walsh, 2016, p. 193). These events averaged about 24 minutes. A high amount of variability exists, with a standard deviation of 29 minutes. In addition to being the most frequent, these standard case contact and interview sessions also ranked number one in terms of total minutes overall at 81,053 (or about 1,351 hours) across all officers and offenders in the study. The need for additional time for these activities was rarely noted with only $5.2 \%$ 
marked as possessing inadequate time. Though not reported in Table 2, the majority of these contact sessions were office visits (81.2\%), some home visits (9.5\%), and a relatively small number of visits to other locations (e.g., place of employment). Further, the bulk of these contacts were recorded by nonspecialized (51.5\%), treatment court (13.3\%), reentry (8.7\%), and ISP officers (7.5\%). The proportion of probationer/parolee contacts outside of the office and at their residence or workplace was less than $20 \%$ for nonspecialized and specialized officers with exception to reentry officers (47\%), IPPOs (32\%), and TAP officers (25\%).

Offender inquiries was the second most commonly recorded activity (7.3\%) averaging about 13 minutes with a standard deviation of 23.4. While these activities were numerous, overall they were not as burdensome, accounting for a total of 17,963 minutes-placing them behind standard contacts, PSIs, violation investigations, report writing/data entry, and court appearances. Having inadequate time for completion was noted for only $7 \%$ of these activities. Questions were predominantly directed towards IPPOs (42.7\%) and nonspecialized officers (33.5\%).

Report writing and data entry responsibilities was the third-most frequent activity recorded, representing 5.7\% of all activities. These took a maximum of 400 minutes (or about 7 hours) but on average required 30 minutes with a standard deviation of 46.5. Documentation may be tied across activities as officers dealt with other issues that interrupted their work. Overall, 29,596 minutes (i.e., 493 hours) were associated with report writing and data entry, placing it behind standard case contacts and PSIs. Officers reported inadequate time for 9\% of these activities. The majority of these activities were documented by nonspecialized officers (39.7\%), IPPOs (17.6\%), treatment court (10.5\%), and reentry officers (9.5\%). The issue of inadequate time for report writing and data entry was more pronounced for the specialized officer working 
with Native Americans (17.2\%) or PSI writers (26.1\%) than nonspecialized officers (10.4\%) or IPPOs (5.7\%).

PSIs were the fourth-most numerous activity documented at 4.9\%. MPPD has a special unit of officers focusing solely on PSIs. PSI writers documented 39.3\% of these activities with nonspecialized officers accounting for another 31.3\%. Officers associated with a sex offender specialization also accounted for another $11.7 \%$ of PSI writing activities. On average officers spent 71.7 minutes at a given time on PSI-related activities with a standard deviation of 71.9. These activities ranked second only to standard case contacts in terms of total volume of time spent by the division at 67,089 minutes (i.e., 1,118 hours). PSI's reflected the highest percentage of activities denoted as having inadequate time for completion at 21.9\%. Looking specifically at PSI writers, the percentage was $15.2 \%$, compared to $22.9 \%$ for nonspecialized officers.

Discharge activities ranked fifth in terms of frequency at $4.3 \%$. These activities concern an offender's discharge from a correctional facility and were primarily the work of IPPOs. Indeed, 93.4\% of these activities were documented by IPPOs with only a small number recorded by specialized and nonspecialized officers. These activities took an average of 17 minutes with a standard deviation of 28.5, though a maximum of 480 minutes was reported (i.e., 8 hours). Total time associated with discharge responsibilities at 14,383 minutes was modest compared to other activity categorizations. Inadequate time for completion was reported for about $8 \%$ of these activities.

Insert Table 2 
Table 3 provides further descriptive data concerning the location, method, and person involved from the activities introduced in Table 2. Most notably, the majority of a probation/parole officer's time was spent with an offender $(60.6 \%)$ in the office (76.8\%). This characteristic is described in the literature as "fortress probation" (Hanser, 2014, p. 132). On average, officers reported spending about a half an hour with offenders in a given contact session, with less than $10 \%$ noting there was inadequate time for these activities. These figures were similar for time spent in the office, but supplemented with time for intra-organizational activities such as collaborating with colleagues. $11.3 \%$ of the activities recorded were solitary in nature and another $8.5 \%$ of activities recorded concerned working with other staff in the division. These findings are unsurprising with exception to the high proportion of office-based work.

Insert Table 3

Table 4 concerns our fourth and final research question; are there significant variations in time associated with probationers/parolees based on office location and offender demographics? This question generated the following hypotheses:

H1: At least one region will be significantly different from one or more of the other regions in terms of the time associated with probationers/parolees.

H2: On average significantly more time will be associated with female probationers/parolees than male probationers/parolees.

H3: On average significantly more time will be associated with Native American or American Indian probationers/parolees than White probationers/parolees.

H4: On average the younger the probationer/parolee the more time will be associated with that individual.

To assess the first hypothesis, a Kruskal-Wallis H test was conducted. The Kruskal-

Wallis $\mathrm{H}$ test is the nonparametric alternative to the one-way ANOVA and it is used to examine 
significant differences between two or more groups of an independent variable on a continuous dependent variable. In this case, the dependent variable is the time (i.e., minutes) associated with an individual probationer/parolee and the independent variable is the region. Compared to the assumptions of a one-way ANOVA, the Kruskal-Wallis $\mathrm{H}$ test does not require normally distributed data or equal variances (Frankfort-Nachmias \& Leon-Guerrero, 2011). As evident from the descriptive information provided in Table 4, specifically the high standard deviations, the time study data are highly skewed and non-normal. Post Hoc analyses, specifically Tamhane for unequal variances, were performed to locate the source of any significant differences from the Kruskal-Wallis $\mathrm{H}$ test.

Note, MPPD possesses six classification levels. One level is intensive supervision, followed by levels I-V with I being the greatest risk and V being the lowest risk. These classification levels are derived from MPPD’s risk assessment and the breakdown of probationers/parolees is provided in Table 4, along with the results of the Kruskal-Wallis $\mathrm{H}$ test performed at each level.

A statistically significant difference in time associated with offenders by region was detected for those under intensive supervision, $\chi^{2}(5)=34.263, p=.001$, with a mean rank score of 171.08 for Region I, 240.48 for Region II, 188.20 for Region III, 233.02 for Region IV, 257.48 for Region V, and 212.48 for Region VI. Post Hoc analyses detected a significant difference between Regions I and V ( $p=.001)$ but not between any other regions.

For level I probationers/parolees, a statistically significant difference in time by region was detected, $\chi^{2}(5)=23.337, p=.001$, with a mean rank score of 175.47 for Region I, 234.24 for Region II, 218.67 for Region III, 227.14 for Region IV, 263.66 for Region V, and 232.81 for 
Region VI. Post Hoc comparisons revealed, again, significant differences between regions I and $\mathrm{V}(p=.043)$ but not between any other regions.

A statistically significant difference was also found for level II probationers/parolees, $\chi^{2}(5)=15.617, p=.008$, with a mean rank score of 336.87 for Region 1, 405.36 for Region II, 369.63 for Region III, 407.53 for Region IV, 414.58 for Region V, and 405.93 for Region VI. There was no significant difference detected for level III offenders, $\chi^{2}(5)=6.898, p=.228$, with a mean rank score of 463.36 for Region I, 512.13 for Region II, 469.76 for Region III, 498.14 for Region IV, 480.02 for Region V, and 543.18 for Region VI.

Level IV offenders exhibited a statistically significant difference, $\chi^{2}(5)=61.798, p=$ .001, with a mean rank score of 426.72 for Region I, 412.74 for Region II, 323.73 for Region III, 276.95 for Region IV, 393.62 for Region V, and 394.21 for Region VI. Post Hoc comparisons revealed significant differences between Regions I and III $(p=.016)$, and I and IV $(p=.045)$.

Finally, Level V offenders exhibited a statistically significant difference, $\chi^{2}(5)=15.833$, $p=.007$, with a mean rank score of 201.88 for Region I, 203.98 for Region II, 189.30 for Region III, 149.66 for Region IV, 164.34 for Region V, and 167.99 for Region VI. Post Hoc comparisons revealed a significant difference between Regions II and IV ( $p=.045)$.

Sex was dichotomously coded with 1 representing male. Race was coded as 1 for Native American or American Indian and 0 for white; the percentage of the population non-white aside from Native American was too small for meaningful statistical comparisons. The Mann-Whitney U statistic, the nonparametric equivalent of a t-test, was used to assess the second and third hypotheses. The Mann-Whitney U test shares the same assumptions as the Kruskal-Wallis H test. In terms of sex, a significant difference was found for intensive supervision probationers/parolees $(U=10090, p=.030)$ with mean ranks of 228.78 for females and 196.08 
for males, as well as with supervision level I $(U=13268, p=.001)$ with mean ranks of 252.92 and 204.96, and level II offenders $(U=49814, p=.001)$ with mean ranks of 420.08 and 358.52 . In other words, females at higher risk levels receive more time than males of similar risk. However, there is no difference in the time associated with males and females at moderate or low risk levels. In terms of Native American or American Indian probationers/parolees compared to white offenders, no statistically significant differences were observed.

Finally, Spearman’s rank-order correlation, a nonparametric alternative to the Pearson product-moment correlation, was used to examine differences in time associated with offenders based on their age. Most noteworthy, Spearman's rank-order correlation does not assume a linear relationship. Significant observations were observed for supervision levels II $\left(r_{s}=-.081, p=\right.$ $.026), \operatorname{IV}\left(r_{s}=-.095, p=.011\right)$, and V $\left(r_{s}=-.219, p=.001\right)$. In all three cases the association was negative and weak, suggesting a slight tendency to spend additional time with younger as opposed to older probationers/parolees. This may simply be the result of younger offenders' lack of familiarity with community supervision.

Insert Table 4

\section{Discussion}

In 2014 the National Governor’s Association (NGA) and the Pew Charitable Trusts (Pew) conducted a brief analysis of MPPD data concerning potential factors that were leading to a rise in Montana’s prison population. Their analyses revealed a large percentage of prison admissions (85\% in 2013) were due to probation and parole revocations, many of which were the result of technical violations. NGA and Pew recommended strengthening the department by 
hiring additional probation/parole officers, providing training on risk assessment and probationer/parolee management, standardizing risk assessment across the state, and, of particular interest to the current study, reducing officer caseload sizes.

The current study revealed how officers spent the majority of their time, on what, with whom, and to what extent time was devoted to probationers/parolees at a given supervision level. Results were similar to prior workload studies conducted at MPPD (Hardyman, 1999, 2001) in terms of the average time associated with a given offender over a one-month period. That said, earlier studies found a distinct discrepancy indicating those at lower supervision levels were, on average, taking more time than those at higher supervision levels. For example, Hardyman (2001) found level III and IV probationers and parolees took more officer time than level II offenders. It is unclear the cause of the discrepancy from this prior research, but the issue appears to have been corrected. The issue could have been the result of poor classification or the lack of adequate reclassification during the course of an individual's supervision. Hardyman's (1999) earlier research results were similar to the current study. Level I offenders took an average of 3.81 hours in 1999, 1.91 in 2001, and 1.66 (99.6 minutes) in 2015. Intensive supervision probationers/parolees averaged 1.91 hours in 1999, 5.97 in 2001, and 1.50 (87.3 minutes) in 2015. The lowest risk population, level V, averaged 0.27 hours in 1999, 0.59 hours in 2001, and 0.55 (33.2 minutes) hours in 2015.

Converting these results to caseload sizes based on existing practices, officers are able to supervise up to 60 level I offenders, 65 intensive supervision offenders, 80 level IIs, 100 level IIIs, 150 level IVs, or 235 level Vs. These rates are, in some instances, high according to APPA's caseload recommendations (Burrell, 2006; Hanser, 2014). As noted earlier, intensive supervision caseloads should be closer to 20:1. Level I probationers and parolees are not far from APPA's 
50:1 recommendation for moderate-to-high-risk individuals but further adjustment is warranted. Discussion of these findings with fellow researchers suggests that MPPD may have too many classification levels. Nonetheless, APPA recommends low risk caseloads of no more than 1:200. As such, level Vs are also not receiving adequate attention. Given that the other classification levels fall on a continuum somewhere between high to low risk it is difficult to set to compare to a specific benchmark. Fortunately, discrepancies in terms of time per probationer/parolee do not appear to be substantially impacted by the offenders' location, sex, race, or age.

Perhaps as a byproduct of large caseloads, MPPD’s probation/parole officers report spending the majority of their time in the office, rather than in the field. While not unusual, especially in relation to low-risk populations, this lack of engagement with offenders outside of the office provides little opportunity to seek out or engage with social work providers and indicates a tendency toward compliance enforcement to the detriment of rehabilitative goals (Skeem \& Manchak, 2008; West \& Seiter, 2004). Indeed, the list of case-related activity codes developed in conjunction with the advisory committee appears skewed towards enforcement goals. The most commonly reported activities represent office contacts and interviews, addressing offenders' questions, report writing and data entry, violation investigations, and urinalysis testing. Aside from the office visit, there appears to be little time or emphasis placed on offender psycho-social needs. Referrals for service, for example, was one of the rarer activities documented in the study. This organizational orientation may play a key role in the high number of revocations for technical violations, contributing to the high jail and prison admissions discussed by NGA and Pew (2014). Continued adoption of EBP under the Smart Probation project is clearly aimed at advancing MPPD activities towards the rehabilitative end of 
the spectrum, which some research has shown when combined with lower caseloads can lead to more positive outcomes (Jalbert \& Rhodes, 2012).

Though the current study does not assess MPPD’s use of EBP, the results should prove informative to further studies in this regard. MPPD recently implemented a new risk assessment instrument and provided motivational interviewing training to its officers. However, the heavy emphasis on office-based supervision and the high number of revocations for technical violations cited by NGA and Pew (2014) suggest that the department still has work to do in terms of incentivizing offenders for good behavior, promoting pro-social networks and behaviors, and engagement in services (for further discussion on what works in reducing recidivism see Fabelo, Nagy, \& Prins, 2011; Latessa, Listwan, \& Koetzle, 2015; for a discussion of staff delivery see Dowden \& Andrews, 2004; Haas \& Spence, 2016). The latest conversation with MDOC leadership and the MPPD advisory committee indicated a desire for additional officers, reportedly up to 20. However, the ability of the department and the division to convince the legislature of this need remains uncertain.

MPPD is well aware their traditional methods of community supervision have failed to produce the outcomes they desire. This study demonstrates that despite recent and ongoing efforts to improve key practices (i.e., changes in risk assessment, training on motivational interviewing), little has changed in officers' level of engagement with offenders since the late 1990s. Indeed, the department must continue to seek out and adopt evidence-based practices that enhance offender reentry (Hanser, 2014). One of the most prominent difficulties MPPD is likely to face in transitioning from a surveillance model to that of an evidence-based hybrid model is the lack of guidance on what actual "practices” at the officer-level, as opposed to system level changes, enable desirable change (Skeem \& Manchak, 2008). As Weisburd, Farrington, and Gill 
(2016) found in their comprehensive review of systematic reviews much of the EBP literature is mixed and does better at revealing what programs or practices do or do not work at the highest level of understanding (i.e., a macro perspective), they do little to provide day-to-day practical guidance to practitioners (a.k.a., service delivery). However, core correctional practices programming has made progress in this area and targets the practices of correctional personnel more directly (Dowden \& Andrews, 2004; see also Schaefer, 2017). Though considered preliminary, a recent meta-analysis of ten studies found significant reductions in recidivism when probation officers had received core correctional practices training compared to probationer populations supervised by officers without such training (Chadwick, Dewolf, \& Serin, 2015).

It is recommended MPPD continue to develop their risk assessment and support the proliferation of motivational interviewing, but also consider adopting core correctional practices training for its community supervision officers. Such an adoption should coincide with revisiting officer workload allocations. Specifically, revised caseload allocations, especially in relation to medium and high risk populations, and improvements in administrative efficiency could help ease the workforces' transition to a new evidence-based hybrid model of supervision (Skeem \& Manchak, 2008), reducing resistance and putting the department on track for improved outcomes in the future. In addition, many states have benefited immensely from the establishment of an evidence-based center (Greenwood, 2014) in turning their operations around. MPPD could similarly benefit from such an arrangement. Such a center could monitor developments in the EBP literature and translate their applicability to the department on a regular basis to ensure they stay apprised of the latest training, programming, and research. 


\section{Limitations}

The current study makes no assumptions about the skills or effectiveness of individual staff members, programs, or agency policies; it does not seek to validate or refute any current practices. Further, temporal biases are often inevitable with any form of cross-sectional research. In this case, MPPD was actively engaged in a variety of implementations before, during, and after the research was conducted, including a new risk assessment instrument and motivational interviewing.

The current study made no attempt to verify the implementation or fidelity of new evidenced-based practices or programs at MPPD introduced shortly before or during the project, an area where further research is warranted. That said, preliminary analyses conducted by NGA and Pew (2014) summarily addresses some of these issues, suggesting that current practices do not produce the desired results (see also Conley \& Schantz, 2006; Conley \& Lake, 2016; Hollist, et al., 2004). Change is needed and the results of this report provide some additional insight into the orientation of officers' workloads, which currently minimize the rehabilitative goals of the department in favor of offender compliance enforcement and administrative work. The current study does not assess or validate the use of MPPD’s risk assessment instruments, the classification methods utilized in relation to those instruments, nor the practices executed by officers at each level of supervision (Clear \& Gallagher, 1985). Finally, the study included no data collection pertaining to case outcomes. Such a study would require a long-term plan far beyond the scope of the current project. While such data could be collected, its association with this specific one-month collection period would be questionable.

Finally, using nonparametric statistics has generally been associated with less power than parametric tests when the assumptions of normality have been confirmed (Fahoome, 2002). 
When faced with skewed data, parametric tests are susceptible to Type I errors (i.e., finding a significant relationship when it does not exist, a.k.a., false positive). Alternatively, nonparametric tests are more susceptible to Type II errors (i.e., confirming the null hypothesis when it is false, a.k.a., false negative). However, this issue was offset by the presence of a large sample size well beyond the minimum requirements of a nonparametric statistic (Fahoome, 2002). Attempts were made to transform the distribution but to no avail. Given these conditions and our research aims, the use of nonparametric statistical tests was appropriate for this study. 


\section{References}

Alghamdi, M. G. (2016). Nursing workload: A concept analysis. Journal of Nursing Management, 24(4), 449-457.

American Prosecutors Research Institute, \& Bureau of Justice Assistance. (2002). How many cases should a prosecutor handle? Results of a national workload asssessment project. Alexandria, VA.

Anderst, J., Teran, P., Dowd, M. D., Simon, S., \& Schnitzer, P. (2015). The association of the Rapid Assessment of Supervision Scale score and unintentional childhood injury. Child Maltreatment, 20(2), 141-145.

Andrews, D. A., Bonta, J., \& Hoge, R. D. (1990). Classification for effective rehabilitation: Rediscovering psychology. Criminal Justice and Behavior, 17(1), 19-52.

Babbie, E. (2007). The practice of social research (11th ed.). Belmont, CA: Thomson Wadsworth.

Bemus, B. (1990). Colorado Judicial Department probation officer workload study. Denver, CO: Office of the State Court Administrator.

Bemus, B., Arling, G., \& Quigley, P. (1983). Workload measures for probation and parole. Washington, DC: U.S. Department of Justice, National Institute of Corrections.

Bercovitz, J., Bemus, B., \& Hendricks, W. S. (1993). Probation case classification \& workload measures system for Indiana. Indianapolis, IN: Indiana Judicial Center.

Bonczar, T. P. (2008). Characteristics of state parole supervising agencies, 2006. Washington, DC: U.S. Department of Justice, Office of Justice Programs, Bureau of Justice Statistics. Burrell, W. D. (2006). Caseload standards for probation and parole. Lexington, KY: Council of State Governments, American Probation and Parole Association. 
Chadwick, N., Dewolf, A., \& Serin, R. (2015). Effectively training community supervision officers. Criminal Justice and Behavior, 42(10), 977-989.

Chapman, J. B. (1972). Workload regulation: The case for purposive action. Probation Journal, 18(1), 8-11.

Clear, T. R., \& Gallagher, K. W. (1985). Probation and parole supervision: A review of current classification practices. Crime \& Delinquency, 31(3), 423-443.

Cobb, K. A., \& Mullins, T. G. (2009). Tribal probation: An overview for tribal court judges. Journal of Court Innovation, 2(2), 329-344.

Conley, T. B., \& Lake, S. (2016). Evaluation of Nexus Treatement Center: A Community Counseling and Correctional Services (CCCS) Department of Corrections contracted program. Missoula, MT: Clinical and Research Consulting.

Conley, T. B., \& Schantz, D. L. (2006). Predicting and reducing recidivism: Factors contributing to recidivism in the state of Montana pre-release center population and the issue of measurement: A report with recommendations for policy change. Missoula, MT: University of Montana, School of Social Work.

Cooper, H. (2010). Research synthesis and meta-analysis: A step-by-step approach (4th ed.). Thousand Oaks, CA: Sage.

Cuddeback, G. S., Gayman, M., \& Bradley-Engen, M. (2011). North Carolina probation/parole caseload standards and practices. Raleigh, NC: North Carolina Department of Corrections.

DeMichele, M. T. (2008). Probation and parole's growing caseloads and workload allocation: Strategies for managerial decision making. Lexington, KY: Council of State Governments, American Probation and Parole Association. 
DeMichele, M. T., \& Payne, B. K. (2007). Probation and parole officers speak out: Caseload and workload allocation. Federal Probation, 71(3), 30-35.

DeMichele, M. T., \& Payne, B. K. (2012). Measuring community corrections' officials perceptions of goals, strategies, and workload from a systems perspective: Differences between directors and nondirectors. The Prison Journal, 92(3), 388-410.

DeMichele, M. T., Payne, B. K., \& Matz, A. K. (2011). Community supervision workload considerations for public safety. Lexington, KY: Council of State Governments, American Probation and Parole Association.

Douglas, J., Tallarico, S., Freiss, E., \& Wills, W. (2004). West Virginia family court judges workload needs assessment. Williamsburg, VA: National Center for State Courts.

Dowden, C., \& Andrews, D. A. (2004). The importance of staff practice in delivering effective correctional treatment: A meta-analytic review of core correctional practices. International Journal of Offender Therapy and Comparative Criminology, 48(2), 203214.

Edwards, A., Hughes, G., \& Lord, N. (2013). Urban security in Europe: Translating a concept in public criminology. European Journal of Criminology, 10(3), 260-283.

Fabelo, T., Nagy, G., \& Prins, S. (2011). A ten-step guide to transforming probation departments to reduce recidivism. New York, NY: Council of State Governments Justice Center.

Fahoome, G. F. (2002). Twenty nonparametric statistics and their large sample approximations. Journal of Modern Applied Statistical Methods, 1(2), 248-268.

Flango, V., \& Ostrom, B. J. (1996). Assessing the need for judges and court support staff. Williamsburg, VA: National Center for State Courts. 
Fletcher, A. J., \& Marchildon, G. P. (2014). Using the Delphi method for qualitative, participatory action research in health leadership. International Journal of Qualitative Methods, 13(1), 1-18.

Frankfort-Nachmias, C., \& Leon-Guerrero, A. (2011). Social statistics for a diverse society (6th ed.). Thousand Oaks, CA: Sage.

Gavrielides, T. (2008). Restorative justice--the perplexing concept: Conceptual fault-lines and power battles within the restorative justice movement. Criminology \& Criminal Justice, $8(2), 165-183$.

Green, R. A. (2014). The Delphi technique in educational research. Sage Open, 4(2), 1-8.

Greenwood, P. (2014). Evidence-based practice in juvenile justice: Progress, challenges, and opportunities. New York, NY: Springer.

Griesse, N. (2008). 2007 workload study. Sioux Falls, SD: State of South Dakota, Board of Pardons and Paroles.

Haas, S. M., \& Spence, D. H. (2016). Use of core correctional practice and inmate preparedness for release. International Journal of Offender Therapy and Comparative Criminology. Advance online publicaton. doi:10.1177/0306624X15625992

Hanser, R. D. (2014). Community corrections (2nd ed.). Thousand Oaks, CA: Sage.

Hardyman, P. L. (1999). Redefining community supervision strategies for Montana Bureau of Probation and Parole. Washington, DC: U.S. Department of Justice, National Institute of Corrections.

Hardyman, P. L. (2001). Computation of the workload formula for the Montana Bureau of Probation and Parole: Revised. Washington, DC: U.S. Department of Justice, National Institute of Corrections. 
Helmer-Hirschberg, O. (1967). Analysis of the future: The Delphi method. Santa Monica, CA: RAND Corporation.

Hollist, D. R., Burfeind, J. W., Doyle, D. P., Conrad, J. A., Price, D. L., Kaikkonen, D. A., \& Soto, D. A. (2004). Chemical dependency treatment and sex offender programming in Montana State Prison: An analysis of the impact of treatment on inmate misconduct and recidivism. Missoula, MT: University of Montana.

Hurst, H. (1999). Workload measurement for juvenile justice system personnel: Practices and Needs [JAIBG Bulletin]. Washington, DC: U.S. Department of Justice, Office of Justice Programs, Office of Juvenile Justice and Delinquency Prevention.

Jalbert, S. K., \& Rhodes, W. (2012). Reduced caseloads improve probation outcomes. Journal of Crime \& Justice, 35(2), 221-238.

Jalbert, S. K., Rhodes, W., Flygare, C., \& Kane, M. (2010). Testing probation outcomes in an evidence-based practice setting: Reduced caseload size and intensive supervision effectiveness. Journal of Offender Rehabilitation, 49(4), 233-253.

Kaeble, D., Bonczar, T. P., \& Maruschak, L. M. (2015). Probation and parole in the United States, 2014. Washington, DC: U.S. Department of Justice, Office of Justice Programs, Bureau of Justice Statistics.

Kleiman, M., Lee, C. G., \& Ostrom, B. J. (2013). Workload assessment: A data-driven management tool for the judicial branch. In The Book of the States (pp. 243-247). Lexington, KY: Council of State Governments.

Latessa, E. J. (2004). The challenge of change: Correctional programs and evidence-based practices. Criminology \& Public Policy, 3(4), 547-560. 
Latessa, E. J., Listwan, S. L., \& Koetzle, D. (2015). What works (and doesn't) in reducing recidivism. New York, NY: Routledge.

Lee, C. G., Kleiman, M., \& Ostrom, B. J. (2014). West Virginia magistrate court workload assessment. Williamsburg, VA: National Center for State Courts.

Lodge, P. (1986). Time for a quiet revolution. Probation Journal, 33(3), 103-105.

Looman, J., Dickie,, I., \& Abracen, J. (2005). Responsivity issues in the treatment of sexual offenders. Trauma, Violence, \& Abuse, 6(4), 330-353.

Lowenkamp, C. T., \& Latessa, E. J. (2005). Increasing the effectiveness of correctional programming through the risk principle: Identifying offenders for residential placement. Criminology \& Public Policy, 4(2), 263-290.

Miles, A. P. (1969). Time studies in probation and parole. Crime \& Delinquency, 15(2), 259-266.

National Governor's Association Center for Best Practices, Pew Charitable Trusts, and Michigan Council on Crime and Delinquency. (2014). Policy options for improving public safety, holding offenders accountable, and containing corrections costs in Montana: Report to the Montana Governor's Office and Department of Corrections. Retrieved September 25, 2015, from http://cor.mt.gov/Portals/104/Resources/Reports/NGAreport2014.pdf

Nugent, M. E., \& Miller, M. L. (2002). Basic factors in determining prosecutor workload. The Prosecutor, 36(4). Retrieved September 25, 2015, from http://ndaa.org/prosecutor_basic_factors_v36no4.html

Orme, J. (1988). Can workloads be measured? Probation Journal, 35(2), 57-59.

Ostrom, B. J., Kleiman, M., Lee, C. G., \& Roth, S. (2014). Assessing feasibility of implementing a senior judge system in the district and circuit courts of Virginia. Williamsburg, VA: National Center for State Courts. 
Paparozzi, M. A., \& Gendreau, P. (2005). An intensive supervision program that worked:

Service delivery, professional orientation, and organizational supportiveness. The Prison Journal, 85(4), 445-466.

Payne, B. K., \& DeMichele, M. T. (2011). Probation philosophies and workload considerations. American Journal of Criminal Justice, 36(1), 29-43.

Schaefer, L. (2017). Correcting the “correctional” component of the corrections officer role: How offender custodians can contribute to rehabilitation and reintegration. Corrections: Policy, Practice and Research. Advance Online Publication. doi:

$10.1080 / 23774657.2017 .1304811$

Skeem, J. L., \& Manchak, S. (2008). Back to the future: From Klockars' model of effective supervision to evidence-based practice in probation. Journal of Offender Rehabilitation, 47(3), 220-247.

Sterling Associates. (2002). Washington State Department of Corrections: Community Corrections: Workload study final report. Author.

Stohr, M. K., \& Walsh, A. (2016). Corrections: The essentials (2nd ed.). Thousand Oaks, CA: Sage.

Tallarico, S., Douglas, J., \& Fogg, V. (2010). North Dakota juvenile court officer weighted workload assessment study. Denver, CO: National Center for State Courts, Court Services Division.

Tallarico, S., Douglas, J., Friess, E., \& Hall, D. J. (2009). Colorado judicial branch probation officer updated workload values study. Denver, CO: National Center for State Courts, Court Services Division. 
Tallarico, S., Douglas, J., Kinney, E., \& Murphy, M. (2007). South Dakota unified judicial system court services officers weighted workload assessment study. Denver, CO: National Center for State Courts, Court Services Division.

Tallarico, S., Douglas, J., Tomlinson, K., \& Hall, D. (2010). Alabama juvenile probation officer weighted workload assessment study. Denver, CO: National Center for State Courts, Court Services Division.

Taxman, F. S., \& Belenko, S. (2012). Implementing evidence-based practices in community corrections and addiction treatment. New York, NY: Springer.

Wagner, D., \& Connell, S. (2004). North Dakota Department of Corrections and Rehabilitation Field Services Division: Probation and parole workload study. Madison, WI: National Council on Crime and Delinquency.

Washington Department of Corrections. (2005). Community corrections workload study final report. Olympia, WA: Author.

Weisburd, D., Farrington, D. P., \& Gill, C. (2016). Conclusion: What works in crime prevention revisited. In D. Weisburd, D. P. Farrington, \& C. Gill (Eds.), What works in crime prevention and rehabilitation: Lessons learned from systematic reviews (pp. 311-326). New York, NY: Springer.

West, A. D., \& Seiter, R. P. (2004). Social worker or cop? Measuring the supervision styles of probation \& parole officers in Kentucky and Missouri. Journal of Crime and Justice, 27(2), 27-57. 
Table 1

Demographics of Probation/Parole Officers and Probationers/Parolees

\begin{tabular}{|c|c|c|c|c|}
\hline \multirow[t]{2}{*}{ Variable } & \multicolumn{2}{|c|}{$\frac{\text { Officers }}{(N=104)}$} & \multicolumn{2}{|c|}{$\frac{\text { Probationers/Parolees }}{(N=4,140)}$} \\
\hline & $N$ & $\%$ & $N$ & $\%$ \\
\hline \multicolumn{5}{|l|}{ Caseload Specialization(s) } \\
\hline Non-Specialized & 46 & 44.2 & 2,047 & 49.4 \\
\hline Institutional Probation/Parole Officer (IPPO) & 16 & 15.4 & 1,033 & 25.0 \\
\hline Intensive Supervision Probation (ISP) & 6 & 5.8 & 156 & 3.8 \\
\hline Mental Health & 5 & 4.8 & 222 & 5.4 \\
\hline Native American & 1 & 1.0 & 39 & 0.9 \\
\hline Presentence Investigation (PSI) Writer & 7 & 6.7 & 104 & 2.5 \\
\hline Reentry & 4 & 3.8 & 124 & 3.0 \\
\hline Sex Offender & 8 & 7.7 & 305 & 7.4 \\
\hline Smart Supervision Program (SSP) Grant & 2 & 1.9 & 67 & 1.6 \\
\hline Treatment Accountability Program (TAP) & 2 & 1.9 & 95 & 2.3 \\
\hline Treatment Court & 7 & 6.7 & 281 & 6.8 \\
\hline \multicolumn{5}{|l|}{ Region and Headquarters } \\
\hline I - Missoula & 21 & 20.2 & 958 & 23.1 \\
\hline II - Helena & 23 & 22.1 & 854 & 20.6 \\
\hline III - Great Falls & 20 & 19.2 & 701 & 16.9 \\
\hline IV - Billings & 19 & 18.3 & 850 & 20.5 \\
\hline V - Kalispell & 14 & 13.5 & 484 & 11.7 \\
\hline VI - Glendive & 7 & 6.7 & 293 & 7.1 \\
\hline \multicolumn{5}{|l|}{ Sex } \\
\hline Male & 53 & 51.0 & 3,202 & 77.3 \\
\hline Female & 51 & 49.0 & 925 & 22.3 \\
\hline Missing & & & 13 & 0.3 \\
\hline \multicolumn{5}{|l|}{ Race } \\
\hline American Indian & & & 744 & 18.1 \\
\hline White & & & 3,258 & 78.7 \\
\hline Other & & & 106 & 2.6 \\
\hline Missing & & & 32 & 0.8 \\
\hline Experience (years) & $M=6.0$ & $S D=3.9$ & & \\
\hline Age (years) & $M=43.0$ & $S D=10.5$ & $M=38.4$ & $S D=12.3$ \\
\hline
\end{tabular}


Table 2

Descriptive Statistics of Case and Non-Case Related Activities

\begin{tabular}{|c|c|c|c|c|c|c|c|}
\hline Activity & $N$ & $\%$ & Max. & $M$ & $S D$ & $\sum$ & $\begin{array}{c}\% \\
\text { Inadequate } \\
\text { Time } \\
\end{array}$ \\
\hline \multicolumn{8}{|l|}{ Case-Related } \\
\hline Standard Case Contact/Interview & 3,449 & 18.1 & 630 & 23.5 & 29.2 & 81,053 & 5.2 \\
\hline Offender Inquiry & 1,396 & 7.3 & 360 & 12.9 & 23.3 & 17,963 & 7.0 \\
\hline Report Writing/Data Entry & 1,094 & 5.7 & 400 & 27.1 & 45.7 & 29,596 & 9.4 \\
\hline Pre-Sentence Investigation (PSI) & 936 & 4.9 & 500 & 71.7 & 71.9 & 67,089 & 21.9 \\
\hline Discharge Activities & 829 & 4.3 & 480 & 17.4 & 28.5 & 14,383 & 7.6 \\
\hline Transition Planning & 757 & 4.0 & 390 & 23.9 & 35.0 & 18,068 & 10.2 \\
\hline Violation Investigation & 605 & 3.2 & 345 & 35.0 & 40.6 & 21,195 & 10.6 \\
\hline Drug Testing (Urinalysis) & 415 & 2.2 & 140 & 17.2 & 19.4 & 7,127 & 6.7 \\
\hline Referral Procedures & 321 & 1.7 & 240 & 29.6 & 30.5 & 9,493 & 7.5 \\
\hline Court Appearances & 303 & 1.6 & 510 & 80.5 & 88.1 & 24,397 & 4.3 \\
\hline Sign-ups/registration & 301 & 1.6 & 690 & 44.0 & 34.8 & 13,233 & 6.3 \\
\hline Risk/Need Assessment & 283 & 1.5 & 300 & 52.95 & 32.9 & 14,984 & 9.5 \\
\hline Transportation Planning & 229 & 1.2 & 180 & 17.0 & 25.8 & 3,881 & 5.7 \\
\hline Revocation Procedures & 225 & 1.2 & 300 & 47.2 & 50.8 & 10,624 & 8.9 \\
\hline Verification Procedures & 208 & 1.1 & 300 & 23.8 & 37.5 & 4,951 & 3.8 \\
\hline Placement Investigations & 179 & 0.9 & 480 & 29.6 & 52.6 & 5,287 & 8.9 \\
\hline Interstate Compact & 111 & 0.6 & 235 & 31.8 & 37.9 & 3,528 & 11.7 \\
\hline GPS Monitoring & 106 & 0.6 & 150 & 21.2 & 27.0 & 2,248 & 8.5 \\
\hline Arrest & 105 & 0.5 & 190 & 50.1 & 39.6 & 5,257 & 2.9 \\
\hline Warrant & 98 & 0.5 & 131 & 15.2 & 17.4 & 1,491 & 3.1 \\
\hline Financial Collection & 95 & 0.5 & 120 & 11.5 & 15.8 & 1,091 & 5.3 \\
\hline Offender Transportation & 84 & 0.4 & 690 & 46.1 & 100.3 & 3,871 & 1.2 \\
\hline Absconder Investigations & 76 & 0.4 & 300 & 41.5 & 55.4 & 3,157 & 17.1 \\
\hline Group Facilitation & 51 & 0.3 & 260 & 84.7 & 64.9 & 4,319 & 2.0 \\
\hline Group Attendance & 51 & 0.3 & 260 & 49.4 & 53.5 & 2,519 & 6.1 \\
\hline Administrative Transfers/Overrides & 50 & 0.3 & 90 & 19.3 & 16.0 & 965 & 6.0 \\
\hline Offender Orientation (IPPO) & 34 & 0.2 & 225 & 36.2 & 45.5 & 1,230 & 5.9 \\
\hline Search Procedures & 33 & 0.2 & 320 & 91.1 & 94.0 & 3,005 & 9.1 \\
\hline Parole Board Hearings & 33 & 0.2 & 370 & 95.0 & 96.0 & 5,287 & 3.0 \\
\hline Sex Offender Registration & 27 & 0.1 & 95 & 24.6 & 20.7 & 663 & 18.5 \\
\hline GPS Installation & 24 & 0.1 & 80 & 31.8 & 22.2 & 763 & 8.3 \\
\hline Evidence Collection/Preservation & 23 & 0.1 & 250 & 63.8 & 79.6 & 1,467 & 8.7 \\
\hline External Database Checks & 9 & 0.0 & 45 & 10.9 & 14.5 & 98 & 0.0 \\
\hline Other & 363 & 1.9 & 220 & 30.6 & 39.2 & 11,097 & 6.1 \\
\hline \multicolumn{8}{|l|}{ Non-Case-Related } \\
\hline Supervisory Functions & 2,110 & 11.1 & 570 & 20.1 & 36.3 & 42,431 & 9.7 \\
\hline Staff Administration & 1,340 & 7.0 & 480 & 31.8 & 42.0 & 42,545 & 12.0 \\
\hline Time Study Documentation & 949 & 5.0 & 560 & 45.8 & 51.9 & 43,468 & 20.3 \\
\hline Work Meetings & 448 & 2.3 & 550 & 46.6 & 71.5 & 20,892 & 4.9 \\
\hline Maintenance & 407 & 2.1 & 480 & 20.9 & 38.6 & 8,486 & 13.0 \\
\hline Staff Leave & 296 & 1.6 & 720 & 251.5 & 233.8 & 74,456 & 7.8 \\
\hline Education/Training/Research & 267 & 1.4 & 720 & 183.2 & 215.4 & 48,913 & 13.9 \\
\hline Coworker Support & 170 & 0.9 & 265 & 23.5 & 40.7 & 3,996 & 7.1 \\
\hline Miscellaneous Mail/Email/Voicemail & 163 & 0.9 & 250 & 38.5 & 51.7 & 6,272 & 5.5 \\
\hline Community Obligations & 41 & 0.2 & 480 & 52.8 & 82.6 & 2,166 & 7.3 \\
\hline
\end{tabular}


Table 3

Characteristics of Activity Contact and Location

\begin{tabular}{|c|c|c|c|c|c|c|c|}
\hline Activity Characteristic & $N$ & $\%$ & Max. & $M$ & $S D$ & $\sum$ & $\begin{array}{c}\% \\
\text { Inadequate } \\
\text { Time } \\
\end{array}$ \\
\hline \multicolumn{8}{|l|}{ Primary Person Involved } \\
\hline Offender & 11,564 & 60.6 & 690 & 28.1 & 40.9 & 324,325 & 8.1 \\
\hline Offender's Guardian or Family & 359 & 1.9 & 225 & 19.9 & 25.2 & 7,137 & 5.0 \\
\hline Absconder & 37 & 0.2 & 300 & 47.1 & 60.1 & 1,743 & 13.5 \\
\hline Victim/Victim's Family & 88 & 0.5 & 240 & 29.3 & 40.0 & 2,575 & 13.6 \\
\hline Staff & 1,627 & 8.5 & 720 & 48.9 & 106.8 & 79,520 & 6.4 \\
\hline Supervisor & 167 & 0.9 & 150 & 22.1 & 23.3 & 3,698 & 10.2 \\
\hline Treatment Provider/Social Service & 781 & 4.1 & 280 & 15.0 & 20.1 & 11,697 & 6.0 \\
\hline Law Enforcement Officer & 290 & 1.5 & 320 & 23.5 & 32.1 & 6,805 & 8.6 \\
\hline Judge & 207 & 1.1 & 350 & 30.6 & 50.7 & 6,341 & 1.9 \\
\hline Attorney & 300 & 1.6 & 170 & 16.7 & 17.2 & 5,016 & 7.0 \\
\hline Public & 103 & 0.5 & 255 & 34.0 & 49.3 & 3,498 & 12.6 \\
\hline Other & 1,406 & 7.4 & 660 & 71.8 & 107.4 & 100,874 & 17.3 \\
\hline Solitary & 2,165 & 11.3 & 720 & 61.7 & 108.6 & 133,623 & 15.1 \\
\hline \multicolumn{8}{|l|}{ Method of Contact } \\
\hline Face-to-Face & 6,849 & 35.9 & 720 & 40.0 & 63.4 & 274,195 & 7.2 \\
\hline Office Telephone & 3,406 & 17.8 & 240 & 12.2 & 15.3 & 41,479 & 7.7 \\
\hline Cell Phone & 326 & 1.7 & 180 & 17.3 & 24.4 & 5,628 & 5.5 \\
\hline Email & 2,066 & 10.8 & 390 & 17.2 & 27.2 & 35,439 & 8.8 \\
\hline Mail & 443 & 2.3 & 150 & 17.5 & 24.6 & 7,746 & 8.1 \\
\hline Joint Face-to-Face & 182 & 1.0 & 285 & 63.0 & 63.2 & 11,468 & 8.2 \\
\hline Other & 5,822 & 30.5 & 720 & 53.4 & 93.2 & 310,897 & 13.1 \\
\hline \multicolumn{8}{|l|}{ Location } \\
\hline Office & 14,672 & 76.8 & 720 & 27.1 & 40.5 & 397,782 & 10.1 \\
\hline Residence & 810 & 4.2 & 560 & 53.9 & 66.3 & 43,649 & 7.4 \\
\hline Employment & 67 & 0.4 & 160 & 27.2 & 29.1 & 1,823 & 6.0 \\
\hline School/University & 14 & 0.1 & 660 & 298.1 & 263.2 & 4,173 & 0.0 \\
\hline Court & 488 & 2.6 & 510 & 68.5 & 83.1 & 33,407 & 3.1 \\
\hline Police/Sheriff's Department & 117 & 0.6 & 320 & 34.7 & 52.0 & 4,054 & 16.2 \\
\hline Jail/Prison & 981 & 5.1 & 630 & 35.0 & 64.7 & 34,257 & 6.5 \\
\hline Treatment Location & 569 & 3.0 & 217 & 27.9 & 33.6 & 15,874 & 3.5 \\
\hline Pre-Release Center & 40 & 0.2 & 275 & 71.0 & 65.5 & 2,839 & 0.0 \\
\hline Group Home & 6 & 0.0 & 73 & 40.8 & 29.0 & 245 & 0.0 \\
\hline Out of Office & 758 & 4.0 & 720 & 142.2 & 192.4 & 109,233 & 8.1 \\
\hline Other & 562 & 2.9 & 720 & 70.3 & 124.9 & 39,516 & 7.7 \\
\hline
\end{tabular}

Notes. $N=19,094$. 
Table 4

Significant Differences in Time Associated with Probationers/Parolees by Supervision Level

\begin{tabular}{|c|c|c|c|c|c|c|c|c|}
\hline \multirow[b]{2}{*}{ Supervision Level } & \multicolumn{4}{|c|}{$\underline{\text { Descriptives }}$} & \multicolumn{4}{|c|}{$\underline{\text { Significant Variations ( } p \text { values) }}$} \\
\hline & $N$ & $M$ & $S D$ & $\sum$ & Region & Sex & Race & Age \\
\hline Intensive & 406 & 87.3 & 125.2 & 35,454 & .001 & .030 & .737 & .334 \\
\hline Level I & 432 & 99.6 & 124.7 & 43,009 & .001 & .001 & .054 & .108 \\
\hline Level II & 753 & 78.8 & 97.3 & 59,329 & .008 & .001 & .757 & .026 \\
\hline Level III & 979 & 63.5 & 87.5 & 62,210 & .228 & .637 & .687 & .102 \\
\hline Level IV & 718 & 42.3 & 72.2 & 30,355 & .001 & .153 & .242 & .011 \\
\hline Level V & 355 & 33.2 & 49.1 & 11,776 & .007 & .376 & .276 & .001 \\
\hline
\end{tabular}

Notes. $N=3,643$. 